\title{
Pulmonary Rehabilitation for Chronic Obstructive Pulmonary Disease: Highly Effective but Often Overlooked
}

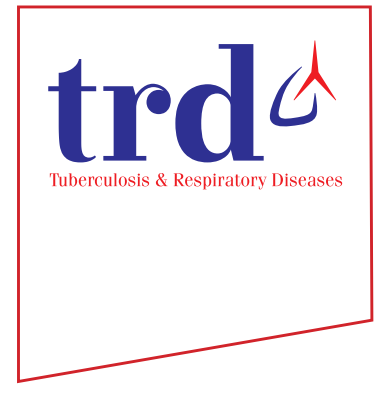

\author{
Michael T. Arnold, M.S., Brett A. Dolezal, Ph.D. and Christopher B. Cooper, M.D. \\ Exercise Physiology Research Laboratory, Departments of Medicine and Physiology, David Geffen School of Medicine, \\ University of California, Los Angeles, CA, USA
}

Patients with chronic obstructive pulmonary disease receive a range of treatments including but not limited to inhaled bronchodilators, inhaled and systemic corticosteroids, supplemental oxygen, and pulmonary rehabilitation. Pulmonary rehabilitation is a multidisciplinary intervention that seeks to combine patient education, exercise, and lifestyle changes into a comprehensive program. Programs 6 to 8 weeks in length have been shown to improve health, reduce dyspnea, increase exercise capacity, improve psychological well-being, and reduce healthcare utilization and hospitalization. Although the use of pulmonary rehabilitation is widely supported by the literature, controversy still exists regarding what should be included in the programs. The goal of this review was to summarize the evidence for pulmonary rehabilitation and identify the areas that hold promise in improving its utilization and effectiveness.

Keywords: Pulmonary Disease, Chronic Obstructive; Pulmonary Rehabilitation; Exercise Limitation; Exercise Prescription

\section{Introduction}

Chronic obstructive pulmonary disease (COPD) is a devastating condition and is currently the third leading cause of mortality worldwide ${ }^{1}$. COPD is also the seventh leading cause of disability-adjusted life years, ranking higher than diabetes mellitus and human immunodeficiency virus/acquired immune deficiency syndrome ${ }^{1}$. In the early stages of the disease,

Address for correspondence: Christopher B. Cooper, M.D.

Exercise Physiology Research Laboratory, Departments of Medicine and Physiology, David Geffen School of Medicine, University of California, Los Angeles 10833 Le Conte Avenue, 43-229 CHS, Los Angeles, CA 900951690, USA

Phone: 1-310-470-3983, Fax: 1-310-206-8211

E-mail: ccooper@mednet.ucla.edu

Received: Jun. 17, 2020

Revised: Jul. 22, 2020

Accepted: Aug. 6, 2020

Published online: Aug. 10, 2020

(c) It is identical to the Creative Commons Attribution Non-Commercial License (http://creativecommons.org/licenses/by-nc/4.0/). patients often limit their physical activity to avoid dyspnea ${ }^{2}$. With disease progression, physical activity ${ }^{3}$ and exercise capacity continue to decline, leading to a vicious cycle of deconditioning, dyspnea, and further reduction in physical inactivity $^{4-6}$. Morning symptoms including coughing and sputum production are also associated with reduced physical activity ${ }^{7}$. Reduced exercise capacity is linked to disability and is a strong predictor of poor health status and early mortality ${ }^{8-10}$. Thus, there is clearly a need to improve exercise capacity and physical activity in COPD patients in order to improve outcomes. Pulmonary rehabilitation (PR) serves that purpose, and is defined as "a comprehensive intervention based on thorough patient assessment followed by patient-tailored therapies that include, but are not limited to exercise training, education, self-management intervention aiming at behavior change, designed to improve the physical and psychological condition of people with chronic respiratory disease and to promote the long-term adherence to health-enhancing behaviors"11. PR is well supported by the literature, and has been shown to improve health status, reduce dyspnea, improve psychological well-being, and reduce healthcare utilization and hospitalization $^{4,11-16}$. Exercise training, in particular, is a highly effective intervention in COPD patients to improve exercise capacity and health status ${ }^{14}$, but it is too often overlooked. In fact, because of the strength of evidence supporting PR, there is a call to cease 
controlled trials comparing PR to standard care ${ }^{17}$. The important question now is how we can continue to improve the outcomes and usage of PR going forward. This review will serve as a summary of the current developments and interventions while identifying burgeoning areas of PR that warrant further investigation.

\section{Pathophysiology of Exercise Limitation}

Exercise limitation in COPD is multifactorial and variabe between patients, with contributions from respiratory impairment, cardiovascular comorbidities and musculoskeletal dysfunction ${ }^{18,19}$. Leg fatigue is commonly cited as a limiting factor for exercise. COPD patients have been shown to have significantly reduced lower limb citrate synthase and 3-hydroxyacyl CoA dehydrogenase enzymes ${ }^{20}$ contributing to reduced muscle oxidative capacity ${ }^{21,22}$. There is a significant correlation between citrate synthase levels and peak exercise capacity, independent of lung function impairment ${ }^{20}$. This is in agreement with other studies showing quadriceps strength to be correlated with exercise capacity independent of respiratory function ${ }^{23,24}$. Lower extremity muscles have also been shown to have fewer type I fibers ${ }^{21}$, and to undergo apoptosis ${ }^{25}$ and atrophy ${ }^{20}$ in COPD patients. This constellation of cellular changes leads to earlier onset of lactic acidosis ${ }^{26}$ and subsequent fatigue at lower levels of exercise performance. Some have attributed these changes to muscular deconditioninga consequence of long-term inactivity and sedentary lifestyle due to disease-related exercise limitation ${ }^{27}$. The changes seen in the skeletal muscles of COPD patients are complex, and there is debate on how much they constitute a true myopathy versus a consequence of inactivity ${ }^{27,28}$. This is by no means a complete list of lower limb muscular dysfunction, but should serve as an introduction to familiarize readers with the major pathologic changes ${ }^{28}$.

Recognizing the importance of air trapping and hyperinflation is key to understanding the pathophysiology of COPD and how it also plays a role in exercise limitation. COPD patients have impaired expiratory flow and therefore reduced lung emptying capacity due to increased airway resistance and reduced lung elastic recoil. During exercise, with increased breathing frequency, there is even less time for lung emptying, which leads to increased end-expiratory lung volume, air trapping, and dynamic hyperinflation ${ }^{29}$. Muscular deconditioning and premature lactic acidosis increases ventilatory requirement during activities of daily living ${ }^{30}$. This increases dynamic hyperinflation, resulting in a decline in physical activity and worsening of other patient-centered outcomes (Figure 1$)^{29}$. The cycle of exercise limitation and de-conditioning is shown diagrammatically in Figure $1^{29}$. Many patients cite the avoidance of dyspnea early in their disease as a cause of decline in physical activity ${ }^{2}$. Because low physical activity is correlated with higher mortality in COPD patients ${ }^{31}$, it is evident that increasing their willingness and ability to exercise should be a goal of treatment. Less than half of all U.S. citizens meet the physical activity guidelines stipulated by the Center for Disease Control for the maintenance of physical wellbeing ${ }^{32}$ and there is growing awareness that healthcare providers should be prescribing physical activity in their practice ${ }^{33}$. As the incidence of COPD rises in an increasingly sedentary population, the prescription for PR is now more pressing than ever.

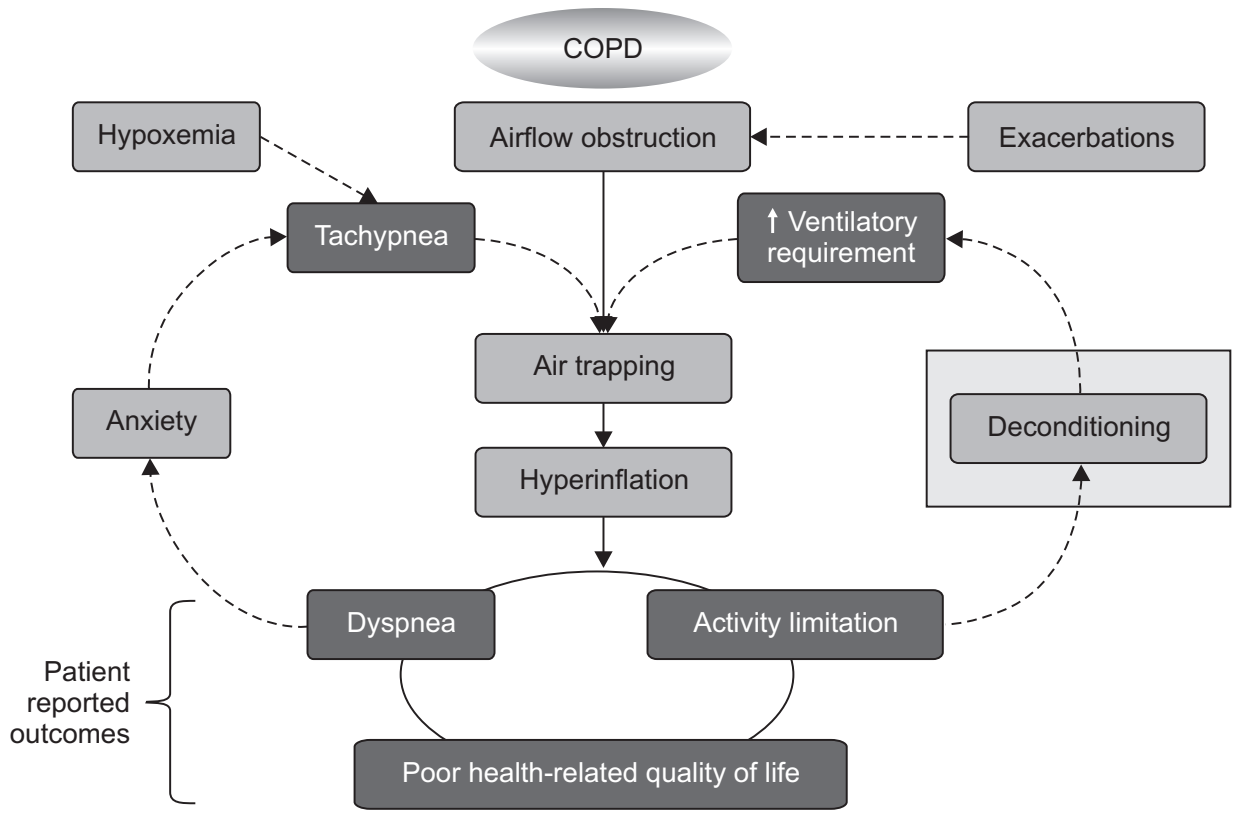

Figure 1. Schematic representation of the pathophysiology of chronic obstructive pulmonary disease (COPD) showing the central role of air-trapping and hyperinflation leading to increased dyspnea, activity limitations and poor health-related quality of life. Exacerbations, which worsen airflow obstruction, physical deconditioning, which increases ventilatory requirements and hypoxemia and/or anxiety, which shorten exhalation time, all aggravate hyperinflation. Reprinted with permission from Cooper CB. Am J Med 2006;119:21-31, with permission of Elsevier $^{29}$. 


\section{Goals of Training and First Steps}

Even though COPD patients have impaired exercise capacity, the core principles of PR should be based on accepted tenets of exercise science. The initial training load should match the particular requirements and health status of the patient but still exceed demands encountered in activities of daily living. The workload should dynamically increase in order to improve muscle conditioning and cardiorespiratory fitness. In COPD patients, rehabilitation is the best way to improve muscle function $^{34-38}$ and it is the most effective intervention to reduce dyspnea and improve health status ${ }^{13}$. Maintenance of physical fitness is a general necessity, even in milder COPD, but patients with moderate to severe disease have the most potential to benefit ${ }^{4}$. The increased oxidative capacity of skeletal muscles leads to decreased ventilatory requirement, reducing exertional dyspnea and dynamic hyperinflation, thus improving exercise capacity. These benefits are even applicable to patients late in the disease course ${ }^{34,39}$ and may also benefit those with chronic hypercapnic ventilatory failure ${ }^{40}$. In addition to the disease-specific improvements from PR, COPD patients also benefit from the ubiquitous benefits of exercise, i.e., effects on improving psychological well-being, decreasing fluctuations in mood, and improving cardiovascular function ${ }^{41}$. These are all contributing factors that make PR a potent intervention in improving health status.

Before being prescribed PR, a thorough initial assessment must be done to ensure the patient is an appropriate candidate and will not be endangered through exercise participation $^{41}$. This assessment should identify the patient's disease stage, specific healthcare needs, smoking status, nutritional health, and social circumstances ${ }^{4,42}$. At this point, it is also pertinent to identify the patient's specific cause of exercise limitation and tailor an exercise program that aligns with their goals of treatment ${ }^{41}$. A patient-centered approach is vital to treatment, which includes setting goals and establishing an action $\operatorname{plan}^{41}$. A clear treatment algorithm, as shown in Figure 2, can be beneficial for providers in educating their patients on how PR fits with their holistic care ${ }^{42}$. These considerations, prior to starting treatment, have been shown to have direct benefits in reducing health care utilization, improving recovery time, and reducing $\operatorname{costs}^{43-47}$. Although education is a necessary first step in behavior change, it is likely not sufficient in providing patients the tools to take action in their own lives. Self-man-

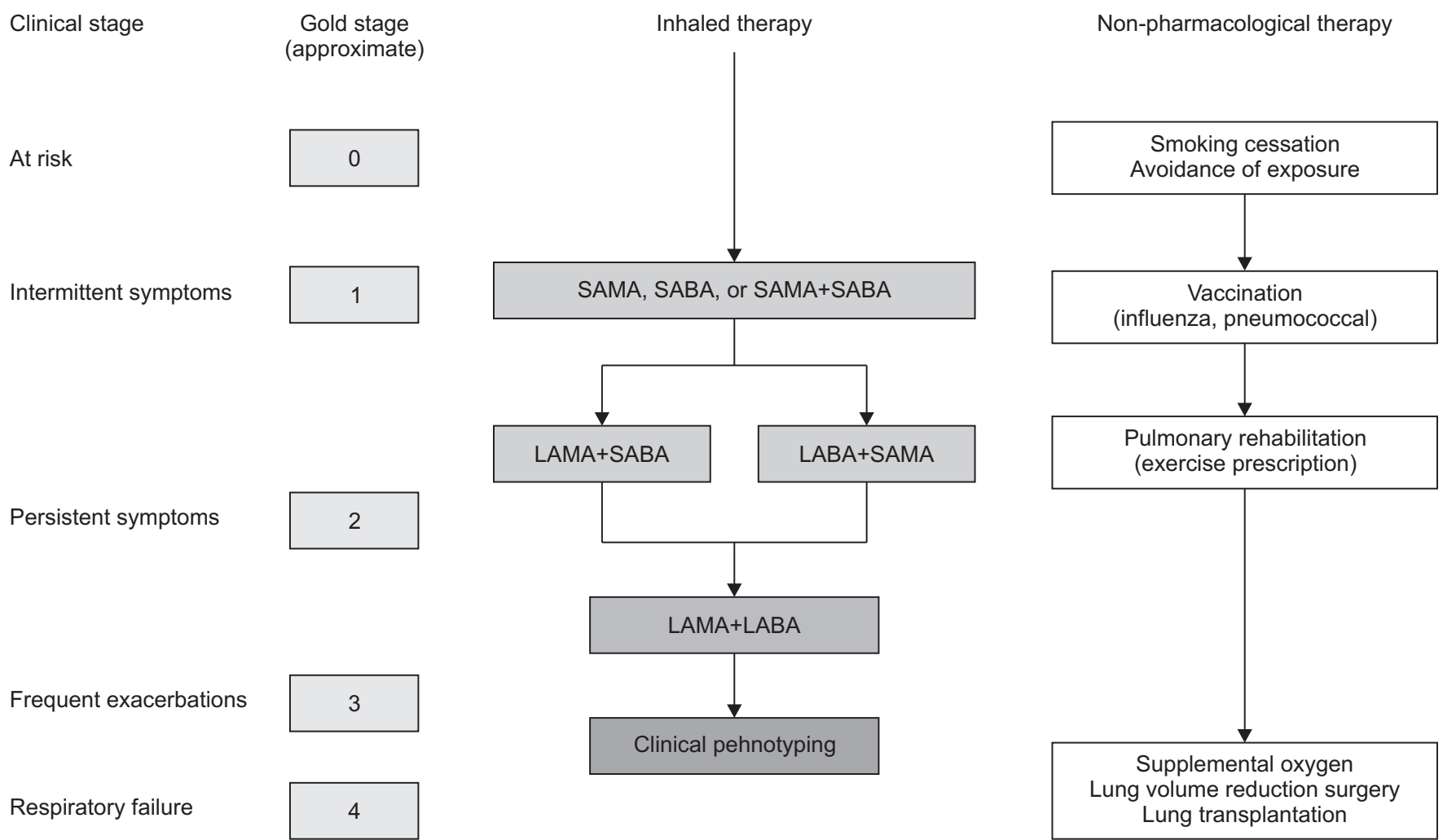

Figure 2. An algorithm for the treatment of chronic obstructive pulmonary disease based on clinical staging. Maintenance long-acting inhaled bronchodilator therapy and pulmonary rehabilitation should be introduced as soon as patients start to exhibit persistent, i.e., daily, symptoms, despite the use of short-acting inhaled bronchodilators. SAMA: short-acting muscarinic antagonists; SABA: short-acting beta agonists; LAMA: long-acting antimuscarinics; LABA: long-acting beta agonists. Reprinted from Cooper CB and Barjaktarevic I. Lancet Respir Med 2015;3:266-8, with permission of Elsevier ${ }^{42}$. 
agement training is a more active form of patient education, which consists of personal care education, motivational interviewing, and skill development in collaboration with trained self-management professionals ${ }^{41}$. Figure 3 shows this process and how it fits into the holistic care model ${ }^{48}$. These interventions are associated with improved health status, a reduction in hospital admission, and improvements in dyspnea ${ }^{49}$. The Global Initiative for chronic Obstructive Lung Disease (GOLD) criteria emphasize the need to assess individual health literacy and self-management capacity, but it should also be a goal to improve these skills throughout the course of treatment as they confer significant improvements in health status ${ }^{50}$.

The chronic care model, for example, is a multidisciplinary approach to chronic disease management that dynamically caters to the individual needs of a patient. It is a widely accepted model in other chronic diseases but is generally lacking in COPD. Although it is still unclear how an organized approach to care such as the chronic care model can promote physical activity in COPD patients ${ }^{51}$, the data suggest the model may reduce hospitalizations in COPD patients ${ }^{52}$. A meta-analysis of integrated disease management programs showed improvements in quality of life, exercise capacity, all aspects of the Chronic Respiratory Questionnaire (dyspnea, fatigue, emotional, and mastery) and a reduction in hospital admissions ${ }^{53}$. These findings support the long-standing notion that well organized care is important, though these needs are frequently overlooked.

\section{Rehabilitation Programs}

Whilst educational components, such as those described above, are routinely incorporated into PR programs, unquestionably, structured exercise training has been recognized as the foundation of a comprehensive program. It is guided by many elements, including type of activity, intensity, duration, frequency, and progression. Additionally, the program should be dynamic yet flexible with modification of these variables depending on the patient's response. Evidence shows that supervised exercise training is better than unsupervised training ${ }^{54}$ and that sessions should be at least twice a week or preferably three times per week ${ }^{55}$. There is insufficient data on which modality of exercise provides optimal benefit ${ }^{4,51}$. With regard to exercise modality, a distinction must be made between methods that are currently supported by evidence and those that are questionably evidence-based ${ }^{14}$. The American College of Chest Physicians/American Association of Cardiovascular and Pulmonary Rehabilitation guidelines recommend the use of upper and lower extremity exercise training, patient education, and resistance training as the core of $\mathrm{PR}^{11}$. Lower extremity endurance exercises such as cycling and treadmill show high grade evidence in improving dyspnea in patients with COPD, making it a highly recommended component of $\mathrm{PR}^{4,11}$. This intuitively makes sense, as a central component in the vicious cycle of exercise limitation is deconditioning of the large muscles of the legs. There is also evidence that a combination of resistance and endurance train-

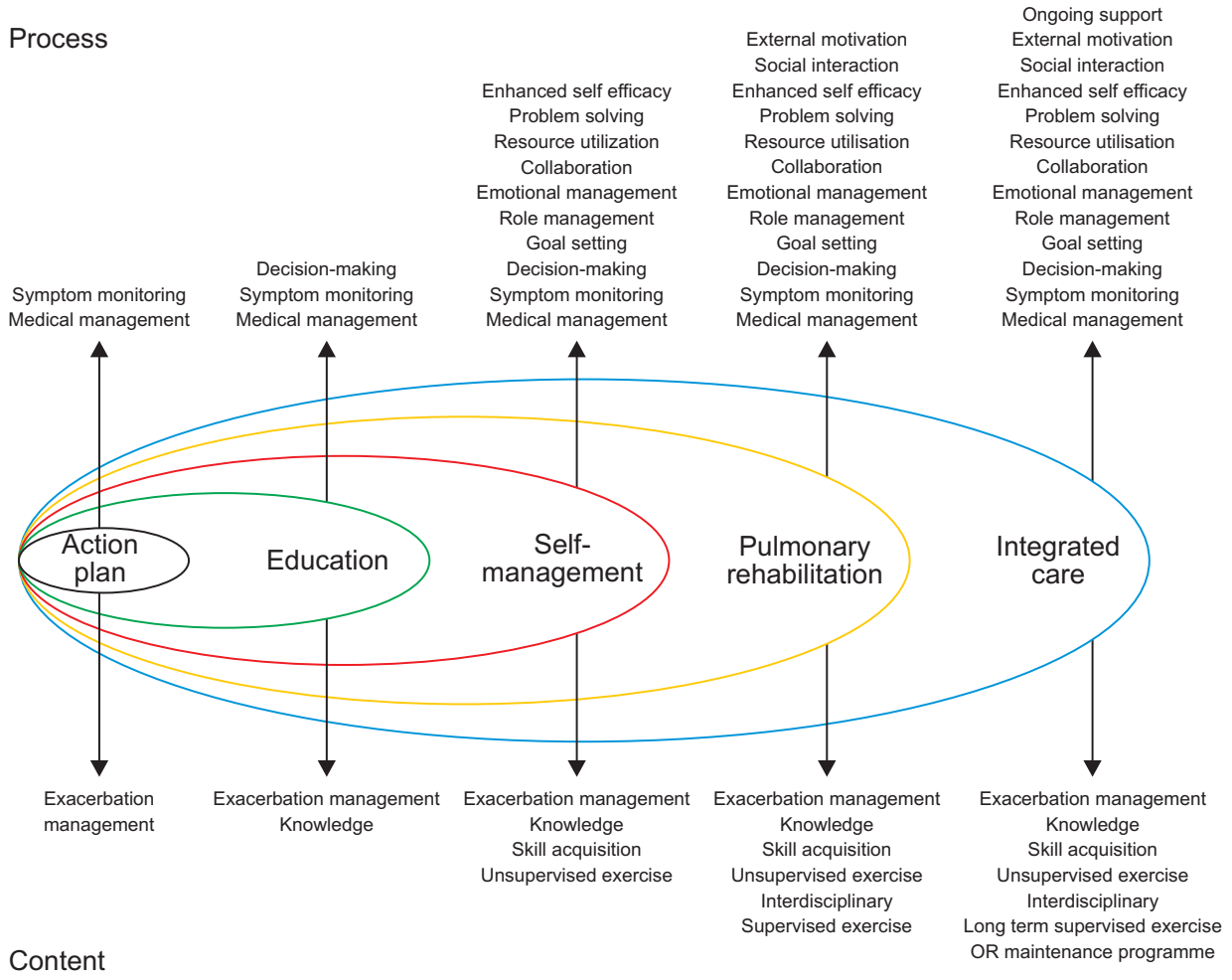

Figure 3. A comprehensive care model for chronic obstructive pulmonary disease that incorporates formulating an action plan, educating patients, developing collaborative self-management, and implementing pulmonary rehabilitation. These elements represent an essential continuum leading to fully integrated care. Reprinted from Wagg K. Chron Respir Dis 2012;9:5-7, with permission of SAGE Publications ${ }^{48}$. 
ing give greater increases in leg muscle strength compared to endurance training alone ${ }^{56}$. The mechanism of PR is multifactorial, but muscular reconditioning through endurance training plays a central role and is demonstrated in Figure $4^{57}$.

Patients see optimal benefits in programs 6 to 8 weeks long, and there is no evidence showing programs 12 weeks or longer provide advantages ${ }^{4}$. In an ideal scenario, all patients after their PR will continue to exercise consistently to maintain their health status and further improve their quality of life. Unfortunately, not all patients will be able to do so. The topic of long-term rehabilitation is controversial and the subject of ongoing research. One promising method is follow-up maintenance exercise, which may prolong some of the clinical benefits for up to 2 years ${ }^{58}$ and further reduce healthcare utilization $^{12}$. In patients who have already undergone rehabilitation, increased levels of physical activity in patients undergoing maintenance programs correlates with improved quality of life and dyspnea ${ }^{58}$. Supervised maintenance exercise following PR may also decrease health care utilization compared to standard $\mathrm{PR}^{12}$. This constellation of findings suggest that maintenance therapy should be considered as a potential next step in the evolution of PR. One question that should be answered is whether or not maintenance therapy needs to be formalized as a specific program or if similar results can be observed in COPD patients who maintain active lifestyles independently.

Casaburi et al. ${ }^{59}$ demonstrated that three, 45 -minute sessions of cycle ergometer training per week for 6 weeks resulted in a progressive increase in work capacity. Higher exercise intensity shows a greater training effect ${ }^{36}$ and may produce superior results in less training time ${ }^{26}$. The increased benefits of higher intensity guide the current recommendation that rehabilitation should be performed at the highest tolerable intensity. Muscle biopsies following training have shown el- evated levels of oxidative enzymes, including citrate synthase and 3-hydroxyacyl-CoA, suggesting an increase in muscular oxidative capacity ${ }^{60}$ which counters the degenerative changes discussed earlier ${ }^{20-22}$. The evidence supporting lower limb endurance training is strong ${ }^{4,11-16}$, but the efficacy of upper limb training is mixed ${ }^{61}$. Upper limb training may reduce dyspnea, but conclusions should be drawn with caution due to heterogeneity of upper limb exercise types ${ }^{61}$. Upper limb exercises are indeed beneficial on their own, but they should not be used as a replacement for lower limb exercise. Instead, they should be combined to maximize beneficial effects. Future randomized controlled trials should explore the benefits of upper limb training combined with lower limb training and what upper limb exercises are most effective.

The incorporation of resistance training in PR is an active area of investigation, but the questions of when and how to use it remain unresolved. Progressive resistance training by itself may lead to significant increases in muscle size, strength, and self-reported health status with equal improvements in symptom burden and exercise capacity compared to endurance training ${ }^{62,63}$. These improvements in muscle strength and size are greater in resistance training compared to endurance training $^{63}$, suggesting that resistance training may have a role in patients with particularly advanced muscle atrophy and deconditioning. In a metanalysis of randomized controlled trials comparing resistance training to aerobic training, there was no significant difference in health status measured by the Chronic Respiratory Questionnaire and no difference in walking distance ${ }^{64}$. Strength training on its own appears to be equally effective compared to endurance training. A combination of resistance training with endrance training may lead to even greater improvements in health status as measured by the total and symptom domain scores of the St. George's Respiratory Questionnaire ${ }^{65}$. A limitation of these results is that

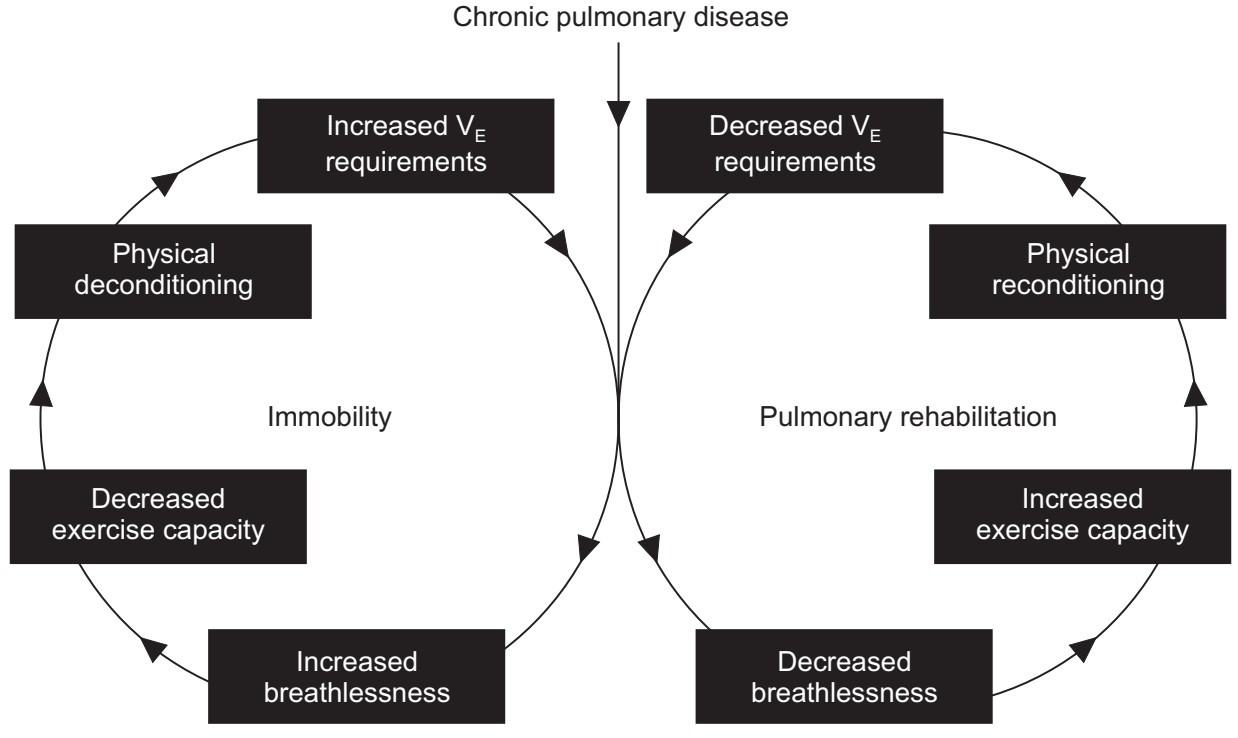

Figure 4. Illustration of the potential of pulmonary rehabilitation for reversing the vicious cycle of deconditioning and declining exercise capacity. Pulmonary rehabilitation leads to the reconditioning of skeletal muscle, a reduction in lactic acidosis, decreased ventilatory requirement, and increased exercise capacity. Reprinted from Cooper CB. Med Sci Sports Exerc 2001;33(7 Suppl):S6719, with permission of Wolters Kluwer Health, Inc. ${ }^{57}$. 
subjects included in these analyses were those who desired to participate in resistance training ${ }^{65}$. Despite this potential for bias, the point remains that patients who are able and willing to perform resistance training in addition to or as an alternative to a standard PR regimen may benefit from improved health status. Some investigators have used resistance training prior to endrance training as a method of preconditioning ${ }^{66}$. This was shown to increase muscle endurance by almost $30 \%$ compared to concurrent resistance and endurance exercise, however this required a 16-week program versus the standard 8 weeks and other clinical outcomes were not significantly different ${ }^{66}$. Future studies should weigh the potential benefits of preconditioning versus the increased time and resources required and whether or not a conjoined program would be a better alternative. Resistance training may also reduce body mass index in obese COPD patients ${ }^{67}$ and can reduce the risk of falls in the elderly ${ }^{68}$, so the benefits of resistance training may vary based on patient characteristics. The lack of definitive superiority of one training method versus the other suggests that PR programs should prescribe a program that suits the patient's own preferences, health status, and characteristics. Future research should identify which patients may benefit most from resistance training, endurance training, or a combination of the two. This further supports the notion that PR must follow a structured, yet adaptive model that meets the specific needs of each patient.

Interval training has become a popular form of exercise for the general population, and it may also have benefits in PR. Patients post-interval versus continuous training show no differences in peak power, peak oxygen uptake, or 6-minute walking distance ${ }^{69,70}$. One purported advantage is that patients in an interval training program are less likely to experience ventilatory limitation, allowing them to reach higher training work rates than would otherwise be attainable ${ }^{71}$. Interval training may have a role in future rehabilitation-particularly for patients who need to maximize skeletal improvements in skeletal muscle performance.

\section{Adjuncts to Pulmonary Rehabilitation}

A number of supplemental interventions may improve the efficacy of PR. The addition of testosterone replacement therapy with resistance training in male patients shows greater improvement in muscle strength than either modality alone ${ }^{72}$. As the incidence of COPD rises with age, it has a greater likelihood of affecting patients after andropause. Measurement of hormone levels prior to rehabilitation, and replacement when indicated, holds promise in maximizing strength gains from training.

COPD patients are at an increased risk for cardiovascular morbidity and mortality ${ }^{73}$. PR may be effective in reducing arterial stiffness ${ }^{74,75}$ and improving ventricular systolic function ${ }^{76}$.
The implications of these findings are unclear, as previous studies have found no changes in mortality following rehabilitation $^{77}$. A possible explanation is that the changes in arterial stiffness may be transient, as these studies did not measure stiffness past 6 weeks. Statin therapy may also improve exercise capacity and pulmonary function for patients with coexisting cardiovascular disease ${ }^{78}$. Further research should examine these potential benefits on a longer time scale and elucidate which exercises are most effective at eliciting this response.

Bronchodilator therapies have an important role in PR also by reducing dyspnea and enabling the patient to exercise at a higher intensity for longer. One study demonstrated that patients on a long-acting maintenance bronchodilator therapy, tiotropium, showed enhanced training effects, with increased physical activity and increased treadmill endurance time $\mathrm{e}^{79-81}$. A mechanism by which inhaled bronchodilators can benefit the COPD patient during physical exertion is by reducing dynamic hyperinflation ${ }^{79}$. This supports the notion that reduction of dyspnea should be made a priority in patients citing it as their primary reason for exercise limitation.

COPD patients often experience falls in oxygen saturation during exercise. Supplemental oxygen is a common intervention used to maintain oxygenation, and it may also have a useful role in rehabilitation. Correction of hypoxemia improves pulmonary vascular conductance, restores normal sleep, and leads to neuropsychiatric improvements ${ }^{82}$. Another effect of correcting hypoxemia is reducing ventilatory drive, which in turn reduces breathing frequency, improves ventilatory efficiency, and reduces dyspnea. Despite these clinical improvements during activities of daily living, supplemental oxygen has not shown an advantage over compressed air when administered during rehabilitative exercise ${ }^{82,83}$. Although supplemental oxygen may not always be necessary during rehabilitation, the ability to prevent desaturation and to enable the patient to exercise at a higher intensity is clearly advantageous.

Inspiratory and expiratory muscle training combined with PR are reported to improve inspiratory muscle strength and exercise limitation although the practical benefits of such a strategy are far from clear $^{84-86}$. Other areas such as nutritional support, sleep quality assurance, and neuromuscular electrical stimulation ${ }^{87}$ show promise as useful adjuncts to PR. There is a small, but growing amount of literature exploring less conventional approaches such as acupuncture ${ }^{88}$, meditation $^{89}$, and Tai $\mathrm{Chi}^{90}$, though there is insufficient evidence at this time to make firm recommendations.

\section{Access to Pulmonary Rehabilitation}

Despite the fact that PR is one of the most cost-effective treatments for COPD, its utilization is often limited by lack of 
awareness and limited patient access ${ }^{91}$. Limited patient access is attributed to many causes including cost, transportation, and geographical location ${ }^{11,92}$. Traditional PR programs have been hospital-based, labor-intensive, and expensive. A promising approach to overcome these issues is the development of community-based exercise programs under the guidance of a certified personal trainers ${ }^{93,94}$. One such program showed increased treadmill endurance after 12 weeks of supervised training and reduced breathlessness, as measured by increased Transition Dyspnea Index focal score ${ }^{94}$. Group based exercise in a similar setting could serve as a motivator for otherwise hesitant patients and it has potential for use as a wider scale intervention for at-risk communities. The standard of care continues to be hospital-based programs, as they form the basis of most scientific evidence generation ${ }^{13}$. Community-based programs may, however, have a place in countries which do not yet have the infrastructure to support dedicated rehabilitation facilities and could potentially improve access. An alternative to community-based programs is home-based PR. A recent randomized controlled trial showed a minimal resource, home-based program offered similar benefits in terms of reduced dyspnea and improved quality of life compared to a traditional center-based program ${ }^{95}$. As telemedicine and remote patient monitoring strategies continue to advance, they will probably further enhance the delivery of remotely-monitored exercise training programs and thus have a role in providing much needed PR services to vulnerable populations. More insidious factors such as fear, lack of motivation, depression, and isolation also serve as barriers to PR and individual exercise routines ${ }^{16,58}$. This lends further credence to the recommendation that rehabilitation should encompass a range of both physical and psychosocial guidance, and that these should be assessed initially, during, and after therapy. Hopefully, the next few years will see a paradigm shioft in the manner by which PR programs are designed and delivered. There is much to be gained by adopting community-based programs and remote patient monitoring with wearable sensors.

\section{Conclusion}

This review gives a summary on the current evidence in favor of PR, highlights gaps in evidence and identifies promising areas of study that warrant further investigation. The literature most strongly supports a $6-8$ week PR program that includes lower extremity endurance and/or resistance exercise and training in collaborative self-management. Training should exceed the loads required for activities of daily living and should increase or decrease according to the progress of the patient. Upper extremity exercises are somewhat effective, but it is doubtful that they can replace lower extremity exercises, thus, only if time allows should they be used in conjunction with leg training using resistance or endurance exercises. Follow-up maintenance therapy is essential to sustain improved clinical outcomes. This is certainly feasible up to 2 years after initial PR, though it has not been demonstrated whether there is benefit beyond this. The benefits of PR should be enhanced by optimizing inhaled bronchodilator therapy and providing supplemental oxygen to exercise-induced prevent desaturation. Other adjuncts to PR such as resistance training and testosterone replacement may further improve clinical outcomes especially when given together. Access to PR remains a pressing issue, but community- and home-based programs are promising solutions. Despite its efficacy, there are still challenges with PR and room for further improvement. A crucial step is education of healthcare providers and patients on the potential benefits and how best to achieve these. PR remains one of the most successful interventions to help COPD patients maintain an active and healthier lifestyle.

\section{Authors' Contributions}

Conceptualization: Cooper CB. Writing - original draft preparation: Arnold MT. Writing - review and editing: Dolezal BA, Cooper CB. Approval of final manuscript: all authors.

\section{Conflicts of Interest}

MTA and BAD report no conflicts of interest. CBC reports grants from NIH/NHLBI, grants from Foundation NIH, grants from COPD Foundation, personal fees from PulmonX, GlaxoSmithKline, NUVAIRA and MGC Diagnostics, outside the submitted work.

\section{Funding}

No funding to declare.

\section{References}

1. World Health Organization. Disease burden and mortality estimates [Internet]. Geneva: World Health Organization; 2020 [cited 2020 Jun 14]. Available from: https://www.who.int/ healthinfo/global_burden_disease/estimates/en/.

2. Witek TJ Jr, Mahler DA. Minimal important difference of the transition dyspnoea index in a multinational clinical trial. Eur Respir J 2003;21:267-72.

3. Waschki B, Kirsten AM, Holz O, Mueller KC, Schaper M, Sack $\mathrm{AL}$, et al. Disease progression and changes in physical activity in patients with chronic obstructive pulmonary disease. Am J Respir Crit Care Med 2015;192:295-306. 
4. Global Initiative for chronic Obstructive Lung Disease (GOLD). Global strategy for the diagnosis, management, and prevention of COPD [Internet]. Fontana, WI: GOLD; 2020 [cited 2020 Jun 14]. Available from: https://goldcopd.org/wp-content/ uploads/2019/12/GOLD-2020-FINAL-ver1.2-03Dec19_WMV. pdf.

5. Pitta F, Troosters T, Spruit MA, Probst VS, Decramer M, Gosselink R. Characteristics of physical activities in daily life in chronic obstructive pulmonary disease. Am J Respir Crit Care Med 2005;171:972-7.

6. Pepin V, Saey D, Laviolette L, Maltais F. Exercise capacity in chronic obstructive pulmonary disease: mechanisms of limitation. COPD 2007;4:195-204.

7. van Buul AR, Kasteleyn MJ, Chavannes NH, Taube C. Association between morning symptoms and physical activity in COPD: a systematic review. Eur Respir Rev 2017;26:160033.

8. American Thoracic Society; American College of Chest Physicians. ATS/ACCP statement on cardiopulmonary exercise testing. Am J Respir Crit Care Med 2003;167:211-77.

9. Oga T, Nishimura K, Tsukino M, Sato S, Hajiro T. Analysis of the factors related to mortality in chronic obstructive pulmonary disease: role of exercise capacity and health status. Am J Respir Crit Care Med 2003;167:544-9.

10. Martinez FJ, Foster G, Curtis JL, Criner G, Weinmann G, Fishman A, et al. Predictors of mortality in patients with emphysema and severe airflow obstruction. Am J Respir Crit Care Med 2006;173:1326-34.

11. Rochester CL, Vogiatzis I, Holland AE, Lareau SC, Marciniuk DD, Puhan MA, et al. An Official American Thoracic Society/ European Respiratory Society policy statement: enhancing implementation, use, and delivery of pulmonary rehabilitation. Am J Respir Crit Care Med 2015;192:1373-86.

12. Jenkins AR, Gowler H, Curtis F, Holden NS, Bridle C, Jones AW. Efficacy of supervised maintenance exercise following pulmonary rehabilitation on health care use: a systematic review and meta-analysis. Int J Chron Obstruct Pulmon Dis 2018;13:257-73.

13. McCarthy B, Casey D, Devane D, Murphy K, Murphy E, Lacasse Y. Pulmonary rehabilitation for chronic obstructive pulmonary disease. Cochrane Database Syst Rev 2015;(2): CD003793.

14. Puhan MA, Gimeno-Santos E, Cates CJ, Troosters T. Pulmonary rehabilitation following exacerbations of chronic obstructive pulmonary disease. Cochrane Database Syst Rev 2016;12:CD005305.

15. Moore E, Palmer T, Newson R, Majeed A, Quint JK, Soljak MA. Pulmonary rehabilitation as a mechanism to reduce hospitalizations for acute exacerbations of COPD: a systematic review and meta-analysis. Chest 2016;150:837-59.

16. Pierobon A, Sini Bottelli E, Ranzini L, Bruschi C, Maestri R, Bertolotti G, et al. COPD patients' self-reported adherence, psychosocial factors and mild cognitive impairment in pulmonary rehabilitation. Int J Chron Obstruct Pulmon Dis
2017;12:2059-67.

17. Lacasse Y, Cates CJ, McCarthy B, Welsh EJ. This Cochrane Review is closed: deciding what constitutes enough research and where next for pulmonary rehabilitation in COPD. Cochrane Database Syst Rev 2015;(11):ED000107.

18. Man WD, Soliman MG, Gearing J, Radford SG, Rafferty GF, Gray BJ, et al. Symptoms and quadriceps fatigability after walking and cycling in chronic obstructive pulmonary disease. Am J Respir Crit Care Med 2003;168:562-7.

19. Pepin V, Saey D, Whittom F, LeBlanc P, Maltais F. Walking versus cycling: sensitivity to bronchodilation in chronic obstructive pulmonary disease. Am J Respir Crit Care Med 2005;172: 1517-22.

20. Bernard S, LeBlanc P, Whittom F, Carrier G, Jobin J, Belleau $\mathrm{R}$, et al. Peripheral muscle weakness in patients with chronic obstructive pulmonary disease. Am J Respir Crit Care Med 1998;158:629-34.

21. Gosker HR, Hesselink MK, Duimel H, Ward KA, Schols AM. Reduced mitochondrial density in the vastus lateralis muscle of patients with COPD. Eur Respir J 2007;30:73-9.

22. Puente-Maestu L, Perez-Parra J, Godoy R, Moreno N, Tejedor A, Gonzalez-Aragoneses F, et al. Abnormal mitochondrial function in locomotor and respiratory muscles of COPD patients. Eur Respir J 2009;33:1045-52.

23. Gosselink R, Troosters T, Decramer M. Peripheral muscle weakness contributes to exercise limitation in COPD. Am J Respir Crit Care Med 1996;153:976-80.

24. Hamilton AL, Killian KJ, Summers E, Jones NL. Muscle strength, symptom intensity, and exercise capacity in patients with cardiorespiratory disorders. Am J Respir Crit Care Med 1995;152(6 Pt 1):2021-31.

25. Agusti AG, Sauleda J, Miralles C, Gomez C, Togores B, Sala E, et al. Skeletal muscle apoptosis and weight loss in chronic obstructive pulmonary disease. Am J Respir Crit Care Med 2002;166:485-9.

26. Casaburi R, Patessio A, Ioli F, Zanaboni S, Donner CF, Wasserman K. Reductions in exercise lactic acidosis and ventilation as a result of exercise training in patients with obstructive lung disease. Am Rev Respir Dis 1991;143:9-18.

27. Wagner PD. Skeletal muscles in chronic obstructive pulmonary disease: deconditioning, or myopathy? Respirology 2006;11:681-6.

28. Maltais F, Decramer M, Casaburi R, Barreiro E, Burelle Y, Debigare R, et al. An official American Thoracic Society/European Respiratory Society statement: update on limb muscle dysfunction in chronic obstructive pulmonary disease. Am J Respir Crit Care Med 2014;189:e15-62.

29. Cooper CB. The connection between chronic obstructive pulmonary disease symptoms and hyperinflation and its impact on exercise and function. Am J Med 2006;119(10 Suppl 1):2131.

30. Vogiatzis I, Zakynthinos S. Factors limiting exercise tolerance in chronic lung diseases. Compr Physiol 2012;2:1779-817. 
31. Garcia-Rio F, Rojo B, Casitas R, Lores V, Madero R, Romero D, et al. Prognostic value of the objective measurement of daily physical activity in patients with COPD. Chest 2012;142:33846.

32. Haskell WL, Lee IM, Pate RR, Powell KE, Blair SN, Franklin BA, et al. Physical activity and public health: updated recommendation for adults from the American College of Sports Medicine and the American Heart Association. Med Sci Sports Exerc 2007;39:1423-34.

33. Myers J. Physical activity: the missing prescription. Eur J Cardiovasc Prev Rehabil 2005;12:85-6.

34. Sala E, Roca J, Marrades RM, Alonso J, Gonzalez De Suso JM, Moreno A, et al. Effects of endurance training on skeletal muscle bioenergetics in chronic obstructive pulmonary disease. Am J Respir Crit Care Med 1999;159:1726-34.

35. Bernard S, Whittom F, Leblanc P, Jobin J, Belleau R, Berube C, et al. Aerobic and strength training in patients with chronic obstructive pulmonary disease. Am J Respir Crit Care Med 1999;159:896-901.

36. Maltais F, LeBlanc P, Simard C, Jobin J, Berube C, Bruneau J, et al. Skeletal muscle adaptation to endurance training in patients with chronic obstructive pulmonary disease. Am J Respir Crit Care Med 1996;154(2 Pt 1):442-7.

37. Griffiths TL, Burr ML, Campbell IA, Lewis-Jenkins V, Mullins J, Shiels K, et al. Results at 1 year of outpatient multidisciplinary pulmonary rehabilitation: a randomised controlled trial. Lancet 2000;355:362-8.

38. Ries AL, Kaplan RM, Limberg TM, Prewitt LM. Effects of pulmonary rehabilitation on physiologic and psychosocial outcomes in patients with chronic obstructive pulmonary disease. Ann Intern Med 1995;122:823-32.

39. Whittom F, Jobin J, Simard PM, Leblanc P, Simard C, Bernard S, et al. Histochemical and morphological characteristics of the vastus lateralis muscle in patients with chronic obstructive pulmonary disease. Med Sci Sports Exerc 1998;30:1467-74.

40. Sahin H, Naz I, Varol Y, Aksel N, Tuksavul F, Ozsoz A. Is a pulmonary rehabilitation program effective in COPD patients with chronic hypercapnic failure? Expert Rev Respir Med 2016;10:593-8.

41. Spruit MA, Singh SJ, Garvey C, ZuWallack R, Nici L, Rochester C, et al. An official American Thoracic Society/European Respiratory Society statement: key concepts and advances in pulmonary rehabilitation. Am J Respir Crit Care Med 2013; 188:e13-64.

42. Cooper CB, Barjaktarevic I. A new algorithm for the management of COPD. Lancet Respir Med 2015;3:266-8.

43. Bischoff EW, Hamd DH, Sedeno M, Benedetti A, Schermer TR, Bernard S, et al. Effects of written action plan adherence on COPD exacerbation recovery. Thorax 2011;66:26-31.

44. Rice KL, Dewan N, Bloomfield HE, Grill J, Schult TM, Nelson $\mathrm{DB}$, et al. Disease management program for chronic obstructive pulmonary disease: a randomized controlled trial. Am J Respir Crit Care Med 2010;182:890-6.
45. Effing T, Monninkhof EM, van der Valk PD, van der Palen J, van Herwaarden CL, Partidge MR, et al. Self-management education for patients with chronic obstructive pulmonary disease. Cochrane Database Syst Rev 2007;(4):CD002990.

46. Trappenburg JC, Monninkhof EM, Bourbeau J, Troosters T, Schrijvers AJ, Verheij TJ, et al. Effect of an action plan with ongoing support by a case manager on exacerbation-related outcome in patients with COPD: a multicentre randomised controlled trial. Thorax 2011;66:977-84.

47. Effing T, Kerstjens H, van der Valk P, Zielhuis G, van der Palen J. (Cost)-effectiveness of self-treatment of exacerbations on the severity of exacerbations in patients with COPD: the COPE II study. Thorax 2009;64:956-62.

48. Wagg K. Unravelling self-management for COPD: what next? Chron Respir Dis 2012;9:5-7.

49. Zwerink M, Brusse-Keizer M, van der Valk PD, Zielhuis GA, Monninkhof EM, van der Palen J, et al. Self management for patients with chronic obstructive pulmonary disease. Cochrane Database Syst Rev 2014;2014:CD002990.

50. Murphy LA, Harrington P, Taylor SJ, Teljeur C, Smith SM, Pinnock H, et al. Clinical-effectiveness of self-management interventions in chronic obstructive pulmonary disease: An overview of reviews. Chron Respir Dis 2017;14:276-88.

51. Burge AT, Cox NS, Abramson MJ, Holland AE. Interventions for promoting physical activity in people with chronic obstructive pulmonary disease (COPD). Cochrane Database Syst Rev 2020;4:CD012626.

52. Adams SG, Smith PK, Allan PF, Anzueto A, Pugh JA, Cornell JE. Systematic review of the chronic care model in chronic obstructive pulmonary disease prevention and management. Arch Intern Med 2007;167:551-61.

53. Kruis AL, Smidt N, Assendelft WJ, Gussekloo J, Boland MR, Rutten-van Molken M, et al. Integrated disease management interventions for patients with chronic obstructive pulmonary disease. Cochrane Database Syst Rev 2013;(10):CD009437.

54. Puente-Maestu L, Sanz ML, Sanz P, Cubillo JM, Mayol J, Casaburi R. Comparison of effects of supervised versus selfmonitored training programmes in patients with chronic obstructive pulmonary disease. Eur Respir J 2000;15:517-25.

55. Ringbaek TJ, Broendum E, Hemmingsen L, Lybeck K, Nielsen D, Andersen C, et al. Rehabilitation of patients with chronic obstructive pulmonary disease: exercise twice a week is not sufficient! Respir Med 2000;94:150-4.

56. Iepsen UW, Jorgensen KJ, Ringbaek T, Hansen H, Skrubbeltrang C, Lange P. A combination of resistance and endurance training increases leg muscle strength in COPD: an evidencebased recommendation based on systematic review with meta-analyses. Chron Respir Dis 2015;12:132-45.

57. Cooper CB. Exercise in chronic pulmonary disease: aerobic exercise prescription. Med Sci Sports Exerc 2001;33(7 Suppl):S671-9.

58. Meshe OF, Claydon LS, Bungay H, Andrew S. The relationship between physical activity and health status in patients with 
chronic obstructive pulmonary disease following pulmonary rehabilitation. Disabil Rehabil 2017;39:746-56.

59. Casaburi R, Porszasz J, Burns MR, Carithers ER, Chang RS, Cooper CB. Physiologic benefits of exercise training in rehabilitation of patients with severe chronic obstructive pulmonary disease. Am J Respir Crit Care Med 1997;155:1541-51.

60. Maltais F, Simard AA, Simard C, Jobin J, Desgagnes P, LeBlanc P. Oxidative capacity of the skeletal muscle and lactic acid kinetics during exercise in normal subjects and in patients with COPD. Am J Respir Crit Care Med 1996;153:288-93.

61. McKeough ZJ, Velloso M, Lima VP, Alison JA. Upper limb exercise training for COPD. Cochrane Database Syst Rev 2016; 11:CD011434.

62. Kongsgaard M, Backer V, Jorgensen K, Kjaer M, Beyer N. Heavy resistance training increases muscle size, strength and physical function in elderly male COPD-patients: a pilot study. Respir Med 2004;98:1000-7.

63. Simpson K, Killian K, McCartney N, Stubbing DG, Jones NL. Randomised controlled trial of weightlifting exercise in patients with chronic airflow limitation. Thorax 1992;47:70-5.

64. Iepsen UW, Jorgensen KJ, Ringbaek T, Hansen H, Skrubbeltrang C, Lange P. A systematic review of resistance training versus endurance training in COPD. J Cardiopulm Rehabil Prev 2015;35:163-72.

65. Liao WH, Chen JW, Chen X, Lin L, Yan HY, Zhou YQ, et al. Impact of resistance training in subjects with COPD: a systematic review and meta-analysis. Respir Care 2015;60:1130-45.

66. Covey MK, Collins EG, Reynertson SI, Dilling DF. Resistance training as a preconditioning strategy for enhancing aerobic exercise training outcomes in COPD. Respir Med 2014;108:1141-52.

67. McDonald VM, Gibson PG, Scott HA, Baines PJ, Hensley MJ, Pretto JJ, et al. Should we treat obesity in COPD? The effects of diet and resistance exercise training. Respirology 2016;21:875-82.

68. Hurley BF, Roth SM. Strength training in the elderly: effects on risk factors for age-related diseases. Sports Med 2000;30:24968.

69. Louvaris Z, Spetsioti S, Kortianou EA, Vasilopoulou M, Nasis I, Kaltsakas G, et al. Interval training induces clinically meaningful effects in daily activity levels in COPD. Eur Respir J 2016;48:567-70.

70. Elkins MR, Dwyer TJ. Interval and continuous training are similarly effective in chronic obstructive pulmonary disease. Br J Sports Med 2011;45:155-6.

71. Porszasz J, Rambod M, van der Vaart H, Rossiter HB, Ma S, Kiledjian R, et al. Sinusoidal high-intensity exercise does not elicit ventilatory limitation in chronic obstructive pulmonary disease. Exp Physiol 2013;98:1102-14.

72. Casaburi R, Bhasin S, Cosentino L, Porszasz J, Somfay A, Lewis MI, et al. Effects of testosterone and resistance training in men with chronic obstructive pulmonary disease. Am J Respir Crit Care Med 2004;170:870-8.
73. Sin DD, Man SF. Chronic obstructive pulmonary disease as a risk factor for cardiovascular morbidity and mortality. Proc Am Thorac Soc 2005;2:8-11.

74. Vivodtzev I, Minet C, Wuyam B, Borel JC, Vottero G, Monneret D, et al. Significant improvement in arterial stiffness after endurance training in patients with COPD. Chest 2010;137:58592.

75. Aldabayan YS, Ridsdale HA, Alrajeh AM, Aldhahir AM, Lemson A, Alqahtani JS, et al. Pulmonary rehabilitation, physical activity and aortic stiffness in COPD. Respir Res 2019;20:166.

76. Bronstad E, Tjonna AE, Rognmo O, Dalen H, Heggli AM, Wisloff $\mathrm{U}$, et al. Aerobic exercise training improves right- and left ventricular systolic function in patients with COPD. COPD 2013;10:300-6.

77. Hakamy A, Bolton CE, McKeever TM. The effect of pulmonary rehabilitation on mortality, balance, and risk of fall in stable patients with chronic obstructive pulmonary disease. Chron Respir Dis 2017;14:54-62.

78. Zhang W, Zhang Y, Li CW, Jones P, Wang C, Fan Y. Effect of Statins on COPD: A Meta-Analysis of Randomized Controlled Trials. Chest 2017;152:1159-68.

79. O'Donnell DE, Fluge T, Gerken F, Hamilton A, Webb K, Aguilaniu B, et al. Effects of tiotropium on lung hyperinflation, dyspnoea and exercise tolerance in COPD. Eur Respir J 2004; 23:832-40.

80. Casaburi R, Kukafka D, Cooper CB, Witek TJ Jr, Kesten S. Improvement in exercise tolerance with the combination of tiotropium and pulmonary rehabilitation in patients with COPD. Chest 2005;127:809-17.

81. Kesten S, Casaburi R, Kukafka D, Cooper CB. Improvement in self-reported exercise participation with the combination of tiotropium and rehabilitative exercise training in COPD patients. Int J Chron Obstruct Pulmon Dis 2008;3:127-36.

82. Heaton RK, Grant I, McSweeny AJ, Adams KM, Petty TL. Psychologic effects of continuous and nocturnal oxygen therapy in hypoxemic chronic obstructive pulmonary disease. Arch Intern Med 1983;143:1941-7.

83. Alison JA, McKeough ZJ, Leung RW, Holland AE, Hill K, Morris NR, et al. Oxygen compared to air during exercise training in COPD with exercise-induced desaturation. Eur Respir J 2019;53:1802429.

84. Neves LF, Reis MH, Plentz RD, Matte DL, Coronel CC, Sbruzzi G. Expiratory and expiratory plus inspiratory muscle training improves respiratory muscle strength in subjects with COPD: systematic review. Respir Care 2014;59:1381-8.

85. Xu W, Li R, Guan L, Wang K, Hu Y, Xu L, et al. Combination of inspiratory and expiratory muscle training in same respiratory cycle versus different cycles in COPD patients: a randomized trial. Respir Res 2018;19:225.

86. O'Brien K, Geddes EL, Reid WD, Brooks D, Crowe J. Inspiratory muscle training compared with other rehabilitation interventions in chronic obstructive pulmonary disease: a systematic review update. J Cardiopulm Rehabil Prev 2008;28:128- 
41.

87. Wouters EF, Posthuma R, Koopman M, Liu WY, Sillen MJ, Hajian B, et al. An update on pulmonary rehabilitation techniques for patients with chronic obstructive pulmonary disease. Expert Rev Respir Med 2020;14:149-61.

88. Coyle ME, Shergis JL, Huang ET, Guo X, Di YM, Zhang A, et al. Acupuncture therapies for chronic obstructive pulmonary disease: a systematic review of randomized, controlled trials. Altern Ther Health Med 2014;20:10-23.

89. Vonbank K, Strasser B, Mondrzyk J, Marzluf BA, Richter B, Losch S, et al. Strength training increases maximum working capacity in patients with COPD: randomized clinical trial comparing three training modalities. Respir Med 2012;106: 557-63.

90. Polkey MI, Qiu ZH, Zhou L, Zhu MD, Wu YX, Chen YY, et al. Tai Chi and pulmonary rehabilitation compared for treatment-naive patients with COPD: a randomized controlled trial. Chest 2018;153:1116-24.

91. Vogiatzis I, Rochester CL, Spruit MA, Troosters T, Clini EM; American Thoracic Society/European Respiratory Society Task Force on Policy in Pulmonary Rehabilitation. Increasing implementation and delivery of pulmonary rehabilitation: key messages from the new ATS/ERS policy statement. Eur Respir J 2016;47:1336-41.

92. Han MK, Martinez CH, Au DH, Bourbeau J, Boyd CM, Branson R, et al. Meeting the challenge of COPD care delivery in the USA: a multiprovider perspective. Lancet Respir Med 2016;4:473-526.

93. Godtfredsen N, Sorensen TB, Lavesen M, Pors B, Dalsgaard LS, Dollerup J, et al. Effects of community-based pulmonary rehabilitation in 33 municipalities in Denmark: results from the KOALA project. Int J Chron Obstruct Pulmon Dis 2019;14: 93-100.

94. Amin S, Abrazado M, Quinn M, Storer TW, Tseng CH, Cooper CB. A controlled study of community-based exercise training in patients with moderate COPD. BMC Pulm Med 2014;14: 125.

95. Holland AE, Mahal A, Hill CJ, Lee AL, Burge AT, Cox NS, et al. Home-based rehabilitation for COPD using minimal resources: a randomised, controlled equivalence trial. Thorax 2017;72:57-65. 